\title{
0 que o Teatro Sabe? : aproximações entre teatro e filosofia para compreender o teatrar
}

\author{
Carlos Eduardo Silva \\ Doutorando em Literatura pelo PPGLIT/UFSC \\ cae.silva@gmail.com
}

O presente artigo reflete sobre uma disciplina que se encarrega de pensar o ser do Teatro, abordando-o desde a Filosofia com o concurso da Ontologia que investiga os entes emergentes do fenômeno teatral e fomenta uma Base Epistemológica da concepção que orienta tais acontecimentos. Além disso, observa-se a relação e as mútuas implicações ocorridas entre essas duas áreas do saber. Para tanto, recorre-se a Krasner e Saltz, pelas intersecções que realizam entre Teatro e Filosofia; a Deleuze, em razão da sua concepção do pensamento filosófico em constante interação com a arte; a Jorge Dubatti, segundo a argumentação que realiza para justificar a criação da referida disciplina; a Bakhtin e Caballero, pela noção de liminaridade, como movimento de trânsito entre estados, paisagens conceituais, etc.; a Pareyson e sua compreensão de estética e poética; a Heidegger, cuja ontologia dedica-se ao entendimento do ente e do ser, que são aplicados ao Teatro; e a Badiou, para tratar das aproximações possíveis entre Filosofia e Arte, especialmente, o Teatro. Por fim, chega-se às estruturas recorrentes que constituem a definição genética de Teatro.

Palavras-chave

Transteatralização. Teatrar. Base Epistemológica. Ontologia. Filosofia do Teatro.
The present article reflects on a discipline that is in charge of thinking the being of the Theater, approached it from Philosophy with the contest of the Ontology that investigates the emerging entities of the theatrical phenomenon and foments an Epistemological Basis of the conception that guides these events. In addition, the relationship and the mutual implications between these two areas of knowledge are observed. To do so, we call Krasner and Saltz, for the intersections between Theater and Philosophy; Deleuze, because of his conception of philosophical thought in constant interaction with art; Jorge Dubatti, according to the argument he makes to justify the creation of said discipline; Bakhtin and Caballero, for the notion of liminality, as a movement of transit between states, conceptual landscapes, etc .; Pareyson and his understanding of aesthetics and poetry; Heidegger, whose ontology is dedicated to the understanding of being and entities, which are applied to the theater; and Badiou, to deal with the possible approximations between Philosophy and Art, especially the theater. Finally, we come to the recurrent structures that constitute the genetic definition of Theater.

Keywords

Transtheatralization. Theatring. Epistemological Basis. Ontology. Philosophy of Theater. 
Eu "tô" em todas, "tô" no ar, eu "tô" aí... eu "tô" até na liquidez do abacaxi

\author{
Naveguei (naveguei) \\ No afã de encontrar (encontrar) \\ Um jeito novo de fazer meu povo de- \\ lirar \\ Uma overdose de alegria \\ Num dilúvio de felicidade (iluminado) \\ lluminado mergulhei \\ No verde branco mar da Mocidade [...] \\ (Medeiros, Tiãozinho, Toco, 1991)
}

O presente artigo busca refletir sobre a necessidade de uma disciplina que se encarregue de pensar o ser do Teatro ocupando-se não apenas do conceito decorrente dessa questão, mas, sobretudo, em obtê-lo desde a Filosofia, observando a relação que se estabelece entre essas duas áreas do saber e as mútuas implicações ocorridas na produção de tal resposta. Para tanto, recorre-se especialmente a Krasner e Saltz, pelas intersecções que realizam entre Teatro e Filosofia; a Deleuze, em razão da sua concepção do pensamento filosófico em constante interação com a arte; e a Jorge Dubatti, segundo a argumentação que realiza para justificar a criação da referida disciplina. Gravitando em torno do tema, dispõe-se de Bakhtin e Caballero, pela noção de liminaridade, como movimento de trânsito entre estados, paisagens conceituais, etc.; Pareyson e sua compreensão de estética e poética; Heidegger, cuja ontologia dedica-se ao que é a obra de arte, o ente e o ser do Teatro; e Badiou, para tratar das aproximações possíveis entre Filosofia e arte, especialmente, o Teatro.

Quando a ingenuidade caminha de mãos dadas com o mundo acadêmico, a sabedoria gargalha ou envergonha-se. Pensar a aproximação entre Teatro e Filosofia como algo novo é ignorar milênios de história. Da cultura popu- lar emerge um caso interessante para iniciar a reflexão: o Grêmio Recreativo Escola de Samba Mocidade Independente de Padre Miguel, do Rio de Janeiro, enfrenta todos os anos um concurso carnavalesco realizado na Marquês de Sapucaí com, no mínimo, outras onze escolas. Até chegar nessa passarela, a referida escola coloca-se na difícil situação de tentar fazer a plateia delirar, ou seja, inventar formas de entreter os brincantes dos dias de Momo até a apoteose, a catarse do folião, numa overdose de alegria, num dilúvio de felicidade durante a passagem da agremiação. Para tanto, a perseguição de descobertas, temas arrebatadores, inovações criativas constitui o incansável ofício dessa, e de todas as escolas de samba, escravizadas pelo eterno retorno da necessidade do novo, ano após ano. E para que? Para fazerem carros alegóricos a partir dos mesmos desenhos, fantasias com os mesmos moldes, sambas segundo as mesmas fórmulas e enredos iguais aos já desenvolvidos anos ou décadas antes. Não quer dizer que o desfile de carnaval seja uma reedição passada, ou mesmo uma repetição interminável, até porque, segundo a teoria da impermanência de Heráclito de Éfeso (540 a.C.), "um não pode entrar duas vezes no mesmo rio [...]" (Kahn, 2009, p. 79), porque, como diz o refrão do samba campeão da Mocidade, "as águas vão rolar" (Medeiros, Tiãozinho, Toco, 1991). Com essa contradição, a obstinação pelo novo torna-se inócua, seja porque tudo é novo ou porque é impossível conhecer-se o passado na sua totalidade para afirmar-se que algo é inovador.

Dessa forma, convém lembrar que o exercício de relacionar o Teatro como alguma outra área do saber não é propriamente algo novo. Ao longo dos anos o Teatro vem sendo abordado a partir de diversas óticas com finali- 
dades muito enriquecedoras para a tradição teatral: o Teatro da perspectiva histórica; da literatura e da antropologia, por exemplo. Em cada movimento onde essas aproximações se tornam possíveis surgiram disciplinas importantes para a reflexão sobre o fazer teatral. Eugênio Barba (2012) contribui enormemente não somente como encenador, mas também como um antropólogo, sendo inegável a influência antropológica de suas pesquisas teatrais a partir da década de 70. Turner (1987) e Schechner (2003) também colaboraram para criar pontes entre Teatro, cultura e rituais, resultando num tratamento específico das teorias da performance, e Zumthor (1983) estabeleceu paralelos entre a literatura e a espetacularidade, no que chamou de performance oral. Como dito, a pluralidade conceitual que surgiu desses contatos e abordagens foi extraordinária, colocando o Teatro como acontecimento artístico fronteiriço e de limites embaçados. Para Dubatti, uma profusão de conceitos surgiu:

Existe já um amplo vocabulário teórico para tratar o tema dos cruzamentos culturais e artísticos. Poderíamos citar alguns desses termos: liminaridade (Turner, Rocco Mangieri), hibridação (Néstor García Canclini), contaminação, fronteiriço (luri Lotman, Mikhail Bakhtin), ex-centris (Linda Hutcheon), complexidade, transversalidade. (Dubatti, 2004, p. 36, tradução minha').

Assim, as inúmeras apropriações feitas por outras disciplinas de termos e conceitos teatrais ocasionou um problema: "já nos primeiros anos do século XX o Teatro se desdelimitou

1 "Existe ya un amplio vocabulario teórico para tratar el tema de los cruces culturales y artísticos. Podríamos enunciar algunos de esos términos: liminalidad (Turner, Rocco Mangieri), hibridación (Néstor García Canclini), contaminación, fronterizo (luri Lotman, Mijail Bajtín), ex-centris (Linda Hutcheon), complejidad, transversalidad" com fenômenos da vida e com outros fenômenos da arte" (Dubatti, 2007, p. 10, tradução minha²). Não à toa, o pesquisador argentino chama este fenômeno de desdelimitação, isto é, a ampliação e consequente desdefinição do fazer teatral, que resultará numa desregulamentação das teorias dos gêneros e da própria teatralidade, como qualidade que determina a característica daquilo que é teatral. Isso é um problema grave na medida em que o Teatro perdendo seus limites, deixa de existir, pois, se tudo é Teatro, nada é Teatro. Afinal, definir ${ }^{3}$, etimologicamente significa justamente, por fim, delimitar, conhecer os limites e a região conceitual da qual se fala. As vanguardas do século XX levaram o Teatro aos locais menos esperados, a herança desse deslocamento é a produção de novas formas de relação humana que se apropriaram de elementos e aspectos teatrais prescindindo do Teatro como até então era conhecido e definido.

Segundo Dubatti (2007), os modelos estáveis da tragédia, comédia, da tragicomédia, da farsa, do drama e do melodrama deixaram de ser vistos como cânones e não se pode definir um conceito fundamental e abarcador de teatralidade que permita congregar as múltiplas formas de acontecer nas poéticas que possui o Teatro. Esse processo de contaminação, hibridização, trânsito ou cruzamento do Teatro com outras formas de arte somado ao uso impreciso e indiscriminado de terminologias das artes cênicas produz um novo e contemporâneo fenômeno, a transteatralização. A Filoso-

2 "Ya en los primeros años del siglo XX el teatro se desdelimitó con fenómenos de la vida y con otros fenómenos del arte."

3 Derivado da palavra latina definire que significa limitar, circunscrever, por fim, terminar, determinar. Declarar de modo preciso e com vocábulos apropriados a natureza de algum assunto. Disponível em: <http://www.etimo.it/?term=definire $>$. Acesso em: 6 jun. 2017. 
fia nomeia seus exemplos, ou casos de uso, de dramatização; a Psicologia estabelece seu psicodrama como técnica terapêutica e avança no sentido de definir uma teoria dos papéis; eventos midiáticos estabelecem que não basta viver a vida, é preciso atuá-la, e professores, advogados, políticos, jornalistas, médicos, juízes, precisam aprender a encenar criando formas ficcionais de converter a realidade objetiva para alcançarem o sucesso em suas carreiras. O Teatro transborda dos palcos para a vida comum, chega à completa diluição dos seus limites, perde seu local e, como diz a letra do samba acima citado, assim como a água, vale ao Teatro dizer: eu "tô" em todas, "tô" no ar, eu "tô" aí, eu "tô" até na liquidez do abacaxi!

Ante esse avassalador processo de descontinuidade e desconstrução teóricas, desdelimitação e transteatralização em que a arte teatral vê-se submetida na contemporaneidade, aparece uma reação que busca a compreensão do que seja o Teatro, refundando-o no encontro efêmero, real e presencial de um acontecimento cuja experiência é irreproduzível por meio técnico. O Teatro deixa de ser a representação ou a apresentação e busca ser experiência e subjetividade. Os saberes inerentes ao fazer teatral precisam ser reorganizados e abordados sem vistas a uma superada essencialidade, mas destacando e potencializando as estruturas recorrentes. Mas não será a Antropologia, a Psicologia, a Literatura ou a Filosofia as áreas capazes de tamanha empreitada, se fosse possível conceituar o Teatro de qualquer um desses locais, deixaria de ser Teatro e seria um apêndice de quem melhor lhe descrevesse. Por isso, ainda que seja muito útil o concurso de outros saberes, apenas o Teatro pode falar de si, refletir a si, revelar os saberes que produz e as experiências que é capaz de proporcionar, enfim, o Teatro teatra! Segundo Dubatti, a Filosofia é uma disciplina que pode auxiliar na compreensão desses saberes, desse teatrar, pois diz o professor portenho:

Os saberes teatrais adquirem a dimensão de "verdades subjetivas" (Sarlo, 2005), e eles reclamam aos estudiosos projetar uma Filosofia das práxis: pensar a experiência, a subjetividade. "O teatro sabe", se diz na Argentina. (Dubatti, 2007, p. 19, tradução minha ${ }^{4}$ ).

Da assertiva anterior surge uma diferença fundamental entre a Filosofia e a Filosofia do Teatro: a busca pela verdade objetiva não constitui o dever e o interesse da prática e da Filosofia teatral, contudo, é alvo da perseguição lógica, ontológica e epistemológica da Filosofia convencional. A Filosofia do Teatro depende da primeira, mas tem por matéria-prima a subjetividade dos acontecimentos imprecisos e efêmeros dessa arte, ancora-se nas práxis, no fazer teatral, isto é, constitui-se como reflexão filosófica empírica e, por isso, não se contenta nem se detém no mundo da especulação, apenas com teses e ideias. A partir desse panorama, a relação entre Teatro e Filosofia pode ser vista com um mergulho razoavelmente mais profundo nessas mesmas "águas", nem sempre calmas, cantadas pela Mocidade.

\section{Zonas de mútuas interferências}

Não me venha com segredos.

$\mathrm{E}$ olha que não acredito em verdades [...]

Verdades são como a sola do sapato

4 "Los saberes teatrales adquieren la dimensión de 'verdades subjetivas' (Sarlo, 2005) y ello reclama a los estudiosos diseñar una filosofía de la praxis: pensar la experiencia, la subjetividad. 'El teatro sabe', se dice en Argentina." 
que cobre a sola do pé.

Você pensa que me dói a brasa na sola do pé,

mas não vê a dor da brasa entre a sola do sapato e a sola do pé.

Pulo, e logo penso: o logos, o fogo.

(Glenadel, 2008, p. 40)

A zona de tensões existente entre Teatro e Filosofia remonta ao princípio da civilização ocidental, isto é, não se trata de uma relação iniciada recentemente por iniciativa da academia. Apesar de muitas ingerências mútuas, muito mais da Filosofia sobre o Teatro que o contrário, verdade seja dita, bem como, conflitos e divergências, existe um aspecto comum entre ambas as áreas e, por isso, especial, que mantém e sustenta essa relação. Sobre essa similitude, Krasner e Saltz afirmam:

O vínculo crítico que mantém o teatro e a Filosofia juntos é o ato de ver. Observar eventos, ações, respostas, gestos e comportamentos, juntamente com ouvir sons, vozes, tons e ritmos, nos aproxima da compreensão das realidades que subjazem as aparências da superfície. [...] Tanto o teatro quanto a Filosofia representam os seres humanos ativamente envolvidos com e no mundo, e uma técnica básica que ambos empregam para esse fim é o diálogo. O diálogo é uma das ferramentas mais importantes do famoso método socrático de Platão e continua a ser um formato comum para apresentar argumentos filosóficos para o esclarecimento. (Krasner; Saltz, 2006, p. 3, tradução minha ${ }^{5}$.

5 "The critical link that holds theater and philosophy together is the act of seeing. Observing events, actions, responses, gestures, and behaviors, along with hearing sounds, voices, tones, and rhythms, brings us closer to understanding the realities that underlie surface appearances.[...] Both theater and philosophy represent humans actively engaging with and in the world, and a basic technique both employ to that end is dialogue. Dialogue is one of the most important tools of Plato's famous Socratic method, and remains a common format for presenting philosophy arguments through the Enlightenment."
Mesmo assim, o exercício de aproximação entre duas áreas precisa ser devidamente justificado para não ser invalidado ou questionado academicamente. A palavra aproximação, indica uma metáfora geográfica onde a distância entre o Teatro e a Filosofia são anuladas para hibridizações mútuas. Porém, para alguns pesquisadores, essa metáfora induz a pensar que se trata de juntar áreas do saber que estavam separadas, no lugar apenas de identificar aquilo que sempre esteve junto, observar as implicações da imanência entre Teatro e Filosofia e, como tal palavra sugere, uma imanência que não permite dizer quem é a origem ou a causa da relação. Portanto, optou-se por recorrer a dois conceitos, o de liminaridade e o de espaços riemannianos. Neles, não há privilégio de um domínio conceitual sobre o outro, todos criam, todos são criadores. Interessa o quanto a Filosofia pode revelar aspectos fundamentais para a compreensão de conceitos importantes no Teatro e vice-versa.

O conceito de liminaridade de Bakhtin, segundo referido em Brait (2010), é aplicado num "regime de tudo o que vive sob fronteiras no espaço dialógico. A liminaridade diz respeito à dinâmica do sistema que permite trânsito entre o externo e o interno". (Machado I, 2003, p. 160) A liminaridade se apresenta como conceito de "trânsito", de movimento entre campos distintos. Esse conceito pode ser tomado como o contrário de inércia ou de estática, pois se trata de uma designação à operação realizada de maneira dinâmica, nem lá, nem cá, nem apenas teatral, nem apenas filosófico. Seria como localizar a reflexão deste artigo na zona de interferências mútuas entre o Teatro e a Filosofia, e esperar que nessa região de intensas turbulências, se pudesse observar as tensões, semelhanças e divergências entre 
essas duas formas de atuação e expressão do pensamento humano.

Para Caballero (2010), esse conceito não é entendido de maneira diversa daquela realizada pelo pensador russo. A liminaridade aparece aplicada no cruzamento de culturas, mas também na ideia de exclusão social onde os limites da sociedade capitalista moderna são evidentes aos que vivem fora dessa fronteira "civilizatória". A arte produzida nessas condições surgiria de uma matéria-prima singular: as experiências dos estados de exceção e produziria discursos não estetizados pela sociedade do espetáculo da realidade objetiva: a dor, a fome, a violência, o sofrimento e, dessa forma, a resistência, a denúncia e o protesto.

A liminaridade não é um conceito estranho à arte, especialmente ao artista cênico, que em si é um ser liminar na execução das suas atribuições da cena, pois que transita entre o universo ficcional e o não ficcional, é e não é o ser fictício. Além disso, esse artista também pode ser um artista-filósofo e, portanto, um artista-criador de conceitos em arte.

Outro conceito importante empregado por Deleuze para justificar a abordagem conjunta das duas áreas, desde que sejam úteis ao projeto filosófico do pensador francês, vem da matemática:

[...] existe um tipo de espaço chamado espaço riemanniano. Matematicamente muito bem definido, com relação às funções, esse tipo de espaço implica a constituição de pequenos pedaços vizinhos cuja ligação pode ser feita de infinitas maneiras, o que permitiu, entre outras, a teoria da relatividade (Deleuze, 1992, p. 158).

Quando se diz que tal área é domínio da Filosofia, da Antropologia ou do Teatro, seria ilusório achar que se tratam de áreas contí- nuas ou contíguas, como países vizinhos, por exemplo. São regiões ou espaços desconexos, cujas ligações podem ser feitas de uma infinidade de maneiras distintas. Por alguma razão etimológica, tende-se a conceber essas disciplinas como extensões espaciais o que leva a utilização de uma terminologia geográfica, como: área, espaço, campo, domínio, etc. Esses termos também aludem ao conjunto de conhecimentos agrupados em vizinhanças comuns como, campo ciência, da Filosofia, e assim por diante. Portanto, quando se refere ao campo da Filosofia ou do Teatro é natural imaginarmos uma área física, geográfica, onde encontrar-se-ia no centro, por exemplo, o Teatro puro e, na direção da extremidade, da fronteira, o único ponto de contato com a área vizinha e passível de contaminação com os domínios alheios.

O que Riemann propõe na matemática é a existência de espaços geométricos que podem produzir infinitos pontos de contato, em planos multidimensionais, com outras regiões que não apenas as bordas. Dessa forma, poder-se-ia dizer que tudo é fronteira. Na presente investigação, não se trata de dizer que no Teatro haja uma região próxima ou distante da Filosofia e vice-e-versa, mas se se tomar unicamente a interpretação desse novo espaço: vizinhanças ligadas de uma infinidade de maneiras possíveis, vizinhanças visuais, sonoras, conceituais, funcionais, ligadas de maneiras diversas e possíveis e não apenas por uma borda imaginária e limítrofe. Então, há um espaço riemanniano onde pode-se pensar o conhecimento específico como potencialidades em trânsito entre Teatro e Filosofia, a depender do impulso que se dê ao movimento do conceito. 


\section{A Filosofia filosofa e o Teatro teatra}

O que me interessa são as relações entre as artes, a ciência e a Filosofia.

(Deleuze,1992, p. 154)

O diretor vai entender o que ele está pensando no processo, porque às vezes o que você está pensando é uma forma aquosa, é uma forma não forma, é uma não forma, você tem uma intuição, uma ideia, uma não forma, é uma massa que você vai polir, você vai lapidar aquela massa. Então, você vai entendendo junto com aqueles companheiros as tuas ideias, aquela tua intuição.

(Olinto, 2015, p. 236)

Os pesquisadores David Krasner e David Z. Saltz (2006) estabelecem uma diferença crucial, sutil e muito interessante entre o Teatro usar a Filosofia e fazer Filosofia. No primeiro caso utilizam-se os conceitos pré-existentes para designar funções ou elementos de um acontecimento teatral. O segundo caso ocorre quando o Teatro busca refletir e especular sobre sua própria feitura na busca de criar ou associar conceitos que dela emerjam. Nos dois casos, o Teatro continua teatrando. A Arte, por sua vez, faz e utiliza a Filosofia numa zona hermenêutica chamada Estética. A qualenfrenta inesgotáveis dificuldades para estabelecer um conceito que compreenda suficientemente a Arte, num campo de tensões nunca será esgotado, justamente porque não cabe à Filosofia dizer em toda a sua totalidade o que é Arte, tampouco fazer arte, e vice-versa. Isso porque a arte não está totalmente no campo do discurso, mas de um enunciado que ultrapassa os limites da linguagem discursiva, da narrativa e da lógica, a arte é experiência sensorial, e pretende produzir experiência até quando é feita na forma de discurso. Arte e Filosofia estão historicamente acopladas numa relação bem expressa pela metáfora criada por Lacan, do Mestre e da Histérica, descrito por Badiou (2002, p. 11-12) abaixo:

\begin{abstract}
Sabe-se que a histérica vem dizer ao mestre: "A verdade fala por minha boca, estou aqui, e tu, que sabes, diga-me quem sou." E advinha-se que, por maior que seja a sutileza douta da resposta do mestre, a histérica lhe dará a entender que ainda não é isso, que seu aqui escapa à apreensão, que se deve retomar tudo e redobrar esforços para lhe agradar. Nesse momento, ela ruma para o mestre e torna-se sua cortesã. E, da mesma maneira, a arte já está sempre aqui, dirigindo ao pensador a questão muda e cintilante de sua identidade, enquanto, por sua constante invenção, por sua metamorfose, ela declara-se decepcionada com tudo o que o filósofo enuncia a seu respeito. O mestre da histérica praticamente não tem outra escolha, caso demonstre má vontade à servidão amorosa, à idolatria que deve pagar com uma produção de saber estafante e sempre decepcionante, a não ser the passar o cetro. E, da mesma maneira, o mestre filósofo permanece dividido, no que diz respeito à arte, entre idolatria e censura. Ou dirá aos jovens, seus discípulos, que o cerne de qualquer educação viril da razão é manter-se afastado da Criatura, ou acabará por conceder que só ela, esse brilho opaco do qual só podemos ser cativos, nos ensine sobre o viés por onde a verdade comanda que o saber seja produzido.
\end{abstract}

Essa anedota demonstra uma insuficiência na relação entre Arte e Filosofia que só se apazigua quando a arte estabelece a sua própria independência e autoridade para legitimar a si mesma, as suas criações e saberes. Dubatti reafirma a capacidade do Teatro de produzir os conhecimentos de que precise para explicarem seu funcionamento, mecanismos e seus artefatos (o resultado ou produto de suas tarefas). Mas, isso é uma afirmação da suficiência 
teatral não um pretexto para fechá-lo numa redoma. De outra parte, a constante insatisfação de ambas as áreas remete à sua tradição histórica, pois faz parte da tradição filosófica ocidental a separação entre homem e natureza, e entre o homem e seus pares considerando a história como distanciador seguro. Isso, para poder separar o observador do objeto observado, distanciar-se criticamente e afastar-se o suficiente para não se envolver e comprometer o resultado da análise.

Tal postura não cabe no Teatro, nem na arte em geral, onde objeto e observador, criador, criação e crítico (ou esteta) se confundem constantemente, o feitor está envolvido com sua obra numa relação inseparável, e onde a recepção ocorre num processo de apropriação da obra. É por isso que Deleuze trata de colocar Ciência, Filosofia e Arte em campos distintos, ainda que haja "interferência, repercussão, ressonâncias entre atividades criadoras sem que haja prioridade de uma sobre as outras" (Machado R, 2010, p. 14). Para o filósofo francês, a Filosofia "[...] se ocupa de conceitos; ela os cria. A pintura cria um determinado tipo de imagens, linhas e cores. O cinema cria outro tipo de imagens, imagens-movimento ou imagens-tempo." (Deleuze, 1992, p. 196). Assim sendo, Deleuze percebe que ter uma ideia em arte não é a mesma coisa que tê-la em Filosofia ou na Ciência, pois "o verdadeiro objeto da ciência é criar funções, o verdadeiro objeto da arte é criar agregados sensíveis, e o objeto da Filosofia, criar conceitos" (Deleuze, 1992, p. 158).

O que Deleuze afirma é algo maior do que uma simples definição, quando o pensador diz que a arte cria agregados sensíveis - ou perceptos-afetos como também se refere - equivale a dizer que criar conceitos não é ação ar- tística, mas da Filosofia, mesmo que seja de uma Filosofia da arte. A tarefa da arte, e nela se inclui o Teatro, é iminentemente voltada à obra de arte, a criação de um poema, uma pintura, escultura, obra cênica, musical, performática, etc., mas quando a arte pensa sobre si e reconstrói sua própria atuação, independente da obra, aproxima-se da Filosofia como criadora de conceitos destinados à compreensão de próprios mecanismos internos e invisíveis à recepção final. Por fim, segundo Deleuze, as criações de perceptos-afetos são resultados de um arranjo de elementos congregados num chamado "plano de composição". Ou seja, uma ideia artística não nasce do nada, mas de um projeto ou sistema que congregue elementos artísticos que permitam seu nascimento. Nesse plano, articulam-se a conceitos, bem como outros perceptos-afetos operados ou não por figuras estéticas - outros artistas ou meros agentes ou influenciadores do sistema artístico em questão. Esse sistema funciona com suas regras próprias, isto é, com sua poética, e produz uma obra ou experiência singular. A Filosofia tem um esquema idêntico, mas chamado plano de imanência, articulando personagens conceituais e conceitos.

Interessante notar que, de acordo com esse filósofo a articulação do plano de composição não obedece apenas e irrestritamente ao programa artístico a que se sintonize, mas sobretudo as forças imprevisíveis e incontroláveis nomeadas intercessores, que são quaisquer encontros que fazem com que o pensamento saia de sua imobilidade natural, de seu estupor. Os intercessores, portanto, são acontecimentos ou eventos que reconfiguram o plano de composição de tal modo que novos encontros entre os elementos que o constituem propiciem a criação artística. Sem os intercessores 
não há criação. Sem eles não há pensamento, razão pela qual se afirma:

O essencial são os intercessores. A criação são os intercessores. Podem ser pessoas - para um filósofo, artistas ou cientistas; para um cientista, filósofos ou artistas - mas também coisas, plantas, até animais, como em Castañeda. Fictícios ou reais, animados ou inanimados, é preciso fabricar seus próprios intercessores (Deleuze, Guattari, 1997, p. 156)

A similaridade do como nasce uma ideia em Arte e Filosofia, diferente apenas na nomenclatura, revela que, para Deleuze, as duas áreas são efetivamente criadoras e não há relação de superioridade entre ambas, além do mais, não seria estranho cruzá-las quando se tratasse da exemplificação ou melhor materializar os conceitos criados no plano de imanência, ou do emprego desses mesmos conceitos nos planos de composição. As incontáveis maneiras com as quais se articulam os elementos constitutivos desses sistemas de criação impedem uma definição homogeneamente e predominantemente aceita sobre o ser do Teatro, no caso específico dessa arte. A impossibilidade dessa definição é menos importante que a preocupação com a identificação da estrutura teatral recorrente e que nos fazem identificar certos acontecimentos como teatrais. Conforme Dubatti, o Teatro se define pelo seu feitio e é justamente essa produção de poièsis ${ }^{6}$, produção de fazeres, que pode ocorrer de diversas maneiras. Baseado nisso, o professor argentino recorre à teoria do reomodo para definir o teatrar, isto é, o conjunto de fazeres ou as práxis do Teatro:

6 Poièsis que do grego refere-se à Poièô, significa inventar, compor, ou simplesmente fazer. Disponível em: <http://www. etimo.it/?term=poesia>. Acesso em: 6 jun. 2017.
[...] utilizando o princípio de reomodo ${ }^{7}$ de David Bohm, [...] para poder compreender a complexidade dos fenômenos, a única maneira de defini-los é utilizar um verbo que nomeie especificamente estes fenômenos, por exemplo: a árvore, absorve a água do solo, tem as raízes subterrâneas, um tronco, sobe aos ares com as ramas, [...] tudo isso somente se pode definir com o verbo "arvorear", a árvore "arvoreia". Como os alunos "aluneiam". A ideia de que os alunos "aluneiam" é a de que saem as oito da manhã de casa, tomam o ônibus, sentam-se na classe, [...] tudo isso seria "alunear". Poderíamos dizer assim, o teatro "teatra". O que seria dizer "o teatro teatra"? 0 teatro faz algo que é tão específico e tão singular, em seu pluralismo, que somente se pode defini-lo com o verbo "teatrar". (Dubatti, 2010a, tradução minha ${ }^{8}$ )

Assim, ter uma ideia em Teatro, ou teatrar (considerando o conjunto de fazeres que dá sentido ao verbo teatrar), revela o que o Teatro sabe, isto é, a especificidade, as características, a perícia que esse fazer demanda dos feitores - seus poetas na acepção original da palavra - a relação que os envolvidos estabelecem entre si e, sobretudo, o conhecimento que só o Teatro articula e do qual é matriz. A

7 Rheo "fluir" em grego, reomodo = modo fluente. "O reomodo envolve, em primeiro lugar, uma nova construção gramatical, onde os verbos são utilizados de uma nova maneira. Todavia o que é mais original é o fato de a sintaxe estender-se não apenas ao arranjo de palavras que podem ser consideradas como já dadas, mas também a um conjunto sistemático de regras para a formação de novas palavras." (Bohm, 2001, p.67)

8 "Utilizando el principio de reo modo de David Bohm [...] para poder entender la complejidad de los fenómenos la única manera de definirlos es utilizando un verbo que nombra específicamente esos fenómenos, por ejemplo, el árbol, absorbe el agua del piso, extiende las raíces hacia abajo, tiene un tronco, sube al alto las ramas, etcétera [...] todo eso solamente se puede definir con el verbo arbolar, el árbol arbola [...] cómo los alumnos alumnean, la idea de que el alumno alumnea sería: sale a las 8 de la mañana de la caso, se toma el colectivo, se sienta a la clase [...]todo eso sería el alumnear. Podríamos decir entonces 'el teatro teatra', que quieres decir 'el teatro teatra'? El teatro hace algo que es tan específico y tan singular en su pluralismo que solamente se puede definir con el verbo teatrar" 
poièsis, ou ação de criar, está relacionada com o ato de dar forma a algo, a uma ideia, desejo, sensação. Conforme Pareyson (1993), a teoria da Formatividade é essa produção de conhecimento a partir da prática, do fazer, esse conceito está notadamente ligado a performatividade, não à toa, com a qual compartilha o radical morfológico. O Teatro é um conjunto de produções poéticas designados como teatrar que não podem ocorrer virtualmente nem no campo das ideias, precisam da presença e da materialidade física. Dubatti recorre aos conceitos de trabalho humano, em Marx (2003), juntamente com o de reprodutibilidade técnica, em Benjamin (1994), para expressar a importância da ação humana não mediada, isto é, do trabalho físico no processo de criação teatral. Por isso, enquanto o plano de imanência filosófico se basta no universo das ideias, com os conceitos que crie, o plano de composição artístico, teatral, se completa na prática. A Filosofia enxerga esse ato artístico da perspectiva ontológica, isto é, da necessidade do fenômeno para fazer, sentir e analisar os elementos efêmeros que surgirem e habitarem tal evento.

A Filosofia do Teatro: base epistemológica e ontologia

Até aqui viu-se que os conceitos teatrais nascem da sua própria feitura, mas falta entender como tais conceitos emergem dessa feitura, são identificados e potencializados em novas feituras de âmbito teatral. Para Dubatti, a Filosofia do Teatro interessa-se por essa relação, ou, mais detalhadamente,

a grande pergunta que faz a Filosofia do teatro seria o que é o teatro, o que podemos chamar teatro e qual o lugar do teatro no concerto de todas as coisas que existem no universo, da natureza, do homem, da ideia de Deus, dos grandes planos da ontologia, da gnosiologia, da ética, não como os grandes ramos do campo filosófico. Se nos perguntamos o que seria o teatro, desde o ponto de vista da Filosofia do teatro, vemos a necessidade de tomar uma posição, uma definição, que leve em conta a complexidade do fenômeno do teatro e, sobretudo, a complexidade atual" (Dubatti, 2010a, tradução minha9).

Cabe a essa disciplina filosófica perscrutar o que o "teatro sabe", com o intuito de edificar uma base epistemológica, que "se pergunta como conhecemos o Teatro, de que concepção formulamos sua existência como acontecimento; e em particular, pergunta que conceito de relação arte e vida torna possível a concepção de uma determinada poética" (Dubatti, 2009, p.10, tradução minha ${ }^{10}$ ). Pois, a cena é uma poética de saberes técnicos e específicos que só se percebe e adquire no comparecimento frequente a essa mesma cena, portanto, a consciência dessa reunião de saberes constitui e enriquece uma base epistêmica que irá inspirar e potencializar novos fazeres. Por isso é importante reconhecer que estes são

saberes que impõem o funcionamento da materialidade primária do teatro: os corpos, o espaço, o tempo do mundo vivente e a singular poièsis que se gera

9 Transcrição: "[...] la gran pregunta que se hace la filosofía del teatro sería que es el teatro, que podemos llamar teatro y que el lugar tiene el teatro en el concierto de todas las cosas que hay en el universo, de la naturaleza, del hombre, de la idea de Dios, los grandes planteos de la ontología, de la gnoseología, los planteos de la ética, no como las grandes ramos del campo filosófico. Si nos preguntamos qué sería el teatro, desde el punto de vista de la filosofía del teatro, vemos la necesidad de tomar una posición, una definición, que tenga en cuenta la complejidad del fenómeno del teatro y, sobre todo, la complejidad actual [...]".

10 "se pregunta cómo conocemos el teatro, desde qué concepciones formulamos su existencia en tanto acontecimiento; y en particular, pregunta qué concepto de la relación arte y vida hace posible la concepción de una determinada poética." 
a partir do trabalho atoral em convívio com artistas, técnicos e espectadores. [...] "O teatro sabe" implica também o reconhecimento de saberes simbólicos-poéticos: o teatro como metáfora epistemológica (em termos de U. Eco, Obra aberta) em cada um dos níveis de sua poética e predicados sobre o mundo. "O teatro pensa", afirma Alain Badiou, porém preferimos "O teatro sabe", porque muitas vezes esses saberes metafóricos da poesia teatral pouco têm a ver com o pensamento a discursividade racionalista -, a Filosofia e a verdade [...] esses saberes só podem ser gerados e percebidos em forma teatral, quer dizer, vivente. (Dubatti, 2007, p. 25, tradução minha ${ }^{11}$ ).

Nesse aspecto, o campo de ação da Filosofia teatral, conforme entendido pelo célebre professor argentino, faz referência à definição de Filosofia da própria arte e seu campo de atuação, segundo o elaborado por Pareyson (1997). Conforme o esteta italiano, a Filosofia da arte desdobra-se em três níveis: o de caráter especulativo e concreto a um só tempo sobre a experiência com a arte; o programa dessa arte, ou seja, o manifesto numa retórica que fundamenta o exercício da atividade artística, os termos normativos e operativos de um determinado gosto e que influenciam esse feitio; e o espelho na qual a obra se reflete, o juízo que se faz de tal obra. Os três níveis revelam-se suscintamente em estética, poética e crítica. De acordo com Dubatti, "o exercício da

11 "Saberes que impone el funcionamiento de la materialidad primaria del teatro: los cuerpos, el espacio, el tiempo del mundo viviente y la singular poíesis que se genera a partir del trabajo actoral en el convivio de artistas, técnicos espectadores. 'El teatro sabe' implica también el reconocimiento de saberes simbólicos-poéticos: el teatro como metáfora epistemológica (en términos de U. Eco, Obra abierta) en cada uno de los niveles de su poética y predicaciones sobre el mundo. 'El teatro piensa', afirma Alain Badiou, pero preferimos 'El teatro sabe', porque muchas veces estos saberes metafóricos de la poesía teatral poco tienen que ver con el pensamiento - la discursividad racionalista -, la filosofía y la verdad [...] esos saberes sólo pueden ser generados y percibidos en forma teatral, es decir, viviente." expectação, da investigação e da crítica teatral converte-se, pela intensidade de sua relação com a cena, numa Filosofia do Teatro " (Dubatti, 2007, p. 23, tradução minha ${ }^{12}$ )

O modo de se pensar e fazer Teatro estimula essa disciplina recente na sua organização chamada Filosofia do Teatro. Para Dubatti, tal disciplina tem um caráter duplo: epistemológico, relacionado com o saber produzido e reconhecido, que se dedica a investigar o que é ter uma ideia teatral, o que inclui sua materialização; e ontológico, que busca quais são os elementos genéticos constitutivos daquilo que se entende pela arte teatral, isto é, quais são os entes teatrais. E nisso não há qualquer diferença entre a Filosofia e a Filosofia do Teatro, a não ser pelo fato de que a segunda se ocupa especificamente do gênero artístico de que roupa o nome:

[...] a Filosofia enquadra nos seus fundamentos a Filosofia do Teatro e é sua condição de possibilidade, mas por sua vez uma Filosofia do Teatro se diferencia da Filosofia somente pelo seu interesse particular no ser peculiar do acontecimento teatral, um ser do estar-acontecer no mundo. (Dubatti, 2010b, p.27, tradução minha ${ }^{13}$ ).

Os procedimentos filosóficos são aplicados nas artes da cena para observar e investigar algo que interessa a essa mesma arte: o ser e os entes do Teatro. Significa afirmar, a partir de Heidegger (2006), que o ser é uma transcendência, a ideia de algo ou de alguma coisa, aquilo que, quando compartilhado e conheci-

12 "El ejercicio de la expectación, la investigación y la crítica teatral devienen, por la intensidad de su relación con la escena, en una filosofía de teatro"

13 "[...] la Filosofía enmarca en sus fundamentos a la Filosofía del Teatro y es su condición de posibilidad, pero a la vez una Filosofía del Teatro se diferencia de la Filosofía a secas por su interés particular en el ser peculiar del acontecimiento teatral, un ser del estar-acontecer en el mundo." 
do pela coletividade, permite o reconhecimento e identificação dessa mesma coisa. O ser nunca é a coisa viva e materializada. $O$ ente, por sua vez, é o ser encarnado, materializado na presença de um acontecimento, no fenômeno daquilo que chamamos, ainda que abstratamente, realidade objetiva ou vida real. $\mathrm{O}$ ser não precisa de mediação para ser entendido, o ente é antes de tudo sentido, pois que, é fruto de uma experiência real e intransferível. Com isso se atende a uma condição essencial e que justifica o desenvolvimento de uma disciplina desse porte e que pode ser definida da seguinte forma:

A Filosofia do Teatro define o teatro como um acontecimento que se diferencia dos outros acontecimentos pela produção de poièsis e expectação em convívio. Admite duas grandes definições de teatro: uma lógico-genética (o teatro consiste na produção de poièsis corporal expectada em convívio); outra pragmática (o teatro consiste na fundação de uma zona de experiência e subjetividade a partir da inter-relação dos subacontecimentos convívio-poièsis-expectação) (Dubatti, 2013, p.71, tradução minha ${ }^{14}$ ).

O acontecimento teatral é o fenômeno onde se materializa o plano de composição. É a instauração de um novo tempo e espaço, efêmero, necessariamente com duração limitada de onde os elementos desse plano viram entes que ganham vida, é um rasgo temporal que se abre e une a dimensão ficcional com a realidade objetiva dando materialidade ao que

14 "La Filosofía del Teatro define el teatro como un acontecimiento que se diferencia de otros acontecimientos por la producción de poièsis y expectación en convivio. Admite dos grandes definiciones del teatro: una lógico-genética (el teatro consiste en la producción de poièsis corporal expectada en convivio); otra pragmática (el teatro consiste en la fundación de un zona de experiencia y subjetividad a partir de la interrelación de los subacontecimientos convivio-poièsis-expectación)." antes era imaginação. A Filosofia do Teatro investiga essas estruturas ontológicas, esses entes, e para chegar nesse conceito identificou-se os entes constitutivos do Teatro como sendo: o convívio, a poièsis e a expectação. "Os aportes da Ontologia ao teatro evidenciam uma nova preocupação pelo ser, já não só pela linguagem, senão por aquilo que o torna possível." (Dubatti, 2010b, p.30, tradução minha ${ }^{15}$ ) A experiência do fenômeno teatral torna-se imprescindível, e inviabiliza circunscrever definições e conhecimentos sobre a cena em dados manifestos somente a priori, é sempre no durante, e eventualmente após, que a vivência do acontecimento e suas implicações se dão. Para Dubatti, "a Ontologia Teatral é o estudo do teatro como acontecimento e produção de entes ou o estudo do acontecimento teatral e dos entes teatrais considerados na sua complexidade ontológica." (Dubatti, 2010b, p.31, tradução minha $\left.{ }^{16}\right)$. Dessa forma, o que permite alcançar a noção de expectação, convívio e poièsis é a aproximação entre Teatro e ontologia por meio do acontecimento teatral onde emergem os entes a serem investigados e, dessa forma, não podem ser conhecidos antes. A partir disso, torna-se mais claro o que afirma o professor Dubatti:

A Filosofia do Teatro afirma que o te-
atro é um acontecimento (no duplo
sentido que Deleuze atribui a ideia de
acontecimento: algo que acontece,
algo no qual se coloca a construção
de sentido), um acontecimento que
produz entes no seu acontecer, ligado
a cultura vivente, a presença aurática

15 "Los aportes de la Ontología al teatro evidencian una nueva preocupación por el ser, ya no sólo por el lenguaje, sino por aquello que lo hace posible."

16 "la Ontología Teatral es el estudio del teatro en tanto acontecimiento y producción de entes o el estudio del acontecimiento teatral y de los entes teatrales considerados en su complejidad ontológica." 
dos corpos, e a partir dessa proposição, elabora argumentos fundamentais que questionam o reducionismo da definição semiótica do teatro [...] (Dubatti, 2010b, p.28, tradução minha ${ }^{17}$ ).

Com a ontologia teatral, busca-se encontrar os elementos genéticos do Teatro, seus entes, aquilo que o constitui enquanto tal e só a ele. Pela definição lógico-genética, Teatro se define como um acontecimento constituído por três subacontecimentos relacionados: o convívio, a poièsis e a expectação. Conforme a definição pragmática, o Teatro gera uma multiplicação mútua dos três subacontecimentos de maneira tal que muitas vezes é impossível distingui- los claramente. Em ambos os casos o Teatro é visto como acontecimento a partir do qual se constitui uma tríade; na primeira concepção, esses componentes estão dados enquanto fundantes; e no segundo, esses componentes formam a matriz multiplicadora e instauradora da zona experiencial possível, seja da cultura vivente ou de subjetividades. Em suma, com base nos estudos e argumentos que permitem a aproximação do Teatro e da Filosofia, pode-se constituir uma concepção de Teatro inicial e, dela, elaborar e acessar uma base epistemológica no decorrer dessa investigação. A concepção de Teatro pode ser definida da seguinte maneira:

Chamaremos concepção de Teatro a forma em que, seja prática (implícita) ou teoricamente (explícita), o Teatro se conceba a si mesmo e conceba suas relações com o concerto do que haja / exista no mundo (o homem, a socie-

\footnotetext{
17 "La Filosofía del Teatro afirma que el teatro es un acontecimiento (en el doble sentido que Deleuze atribuye a la idea de acontecimiento: algo que acontece, algo en lo que se coloca la construcción de sentido), un acontecimiento que produce entes en su acontecer, ligado a la cultura viviente, a la presencia aurática de los cuerpos, y a partir de esa proposición, elabora argumentos fundamentales que cuestionan el reduccionismo de la definición semiótica del teatro [...]"
}

dade, o sagrado, a linguagem, a política, a ciência, a educação, o sexo, a economia, etc.). (Dubatti, 2009, p. 9, tradução minha ${ }^{18}$ )

Por fim, o estudo das circunstâncias nas quais ocorre a constituição da poética teatral, sua matéria-prima, seus agentes constitutivos, a relação imprevisível entre tais elementos que ganham corpo, gestos, ações e movimentos no acontecimento teatral fomenta a base epistemológica e a ontologia de uma Filosofia que tem no Teatro, seu objeto principal. Contudo, resta uma última reflexão ao investigador teatral, a saber, quão interessante e útil é uma disciplina que visa potencializar e priorizar uma certa feitura se os métodos filosóficos empregados, incluindo os conceitos tratados, nos forem desconhecidos? A Filosofia do Teatro não torna filósofo aquele que por ela se interessar, mas obrigatoriamente demanda um diálogo com uma dupla tradição, a teatral e a filosófica, para evitar empregos descontextualizados de grandes pensadores, por exemplo.

Referências

BADIOU, Alain. Pequeno manual de inestética. Tradução de Marina Appenzeller. São Paulo: Estação Liberdade, 2002.

BARBA, Eugênio; SAVARESE, Nicola. $A$ arte secreta do ator: um dicionário de antropologia teatral. Tradução de Patrícia Furtado de Mendonça. São Paulo: Realizações Editora, 2012.

BENJAMIN, W. A Obra de arte na era de sua reprodutibilidade técnica. In: Magia e

18 "Llamamos concepción de teatro a la forma en que, ya sea práctica (implícita) o teóricamente (explícita), el teatro se concibe a sí mismo y concibe su relaciones con el concierto de lo que hay/existe en el mundo (el hombre la sociedad, lo sagrado, el lenguaje, la política, la ciencia, la educación, el sexo, la economía, etc.)." 
técnica, arte e política: ensaios sobre Literatura e História da Cultura. Obras Escolhidas. v. 1. São Paulo: Brasiliense, 1994.

BOHM, David. A totalidade e a ordem implicada: uma nova percepção da realidade. 12. ed. Tradução de Mauro de Campos Silva. São Paulo: Cultrix, 2001.

BRAIT, B. (Org.). Bakhtin: outros conceitos-chave. São Paulo: Contexto, 2010.

CABALLERO, Ileana Diéguez. Cenários Liminares: teatralidades, performances e política. Uberlândia: UDUFU, 2011.

DELEUZE, Gilles. Conversações (1972-1990). Tradução de Peter Pál Pelbrat. São Paulo: 34, 1992.

DELEUZE, Gilles; GUATTARI, Félix. O que é Filosofia? Tradução de Bento Prado Jr. e Alberto Alonso Muñoz. São Paulo: 34, 1997.

DUBATTI, Jorge. Filosofía del Teatro I: Convivio, experiencia, subjetividad. Buenos Aires: Atuel, 2007.

Concepciones de Teatro: Poéticas teatrales y bases epistemológicas. Buenos Aires: Colihue, 2009.

Conferência sobre Filosofía del Teatro. Universidad de Monterrey, 2010a. Disponível em: <https://www.youtube.com/watch?v=UQfwvdLvZIQ>. Acesso em: 2 jun. 2017.

Filosofía del Teatro II: Cuerpo poético y función ontológica. Buenos Aires: Atuel, 2010b.

. Teatro, arte, ciencias del arte y epistemología: una introduccíon. In: Revista Repertório: Teatro \& Dança. Ano 16, Número 20, p.65-76. Salvador: 2013.

GLENADEL, Paula. A fábrica do feminino. Rio de Janeiro: 7Letras, 2008.
HEIDEGGER, Martin. Ser e Tempo. Tradução de Márcia Sá Cavalcante Schuback. Petrópolis: Vozes, 2006.

KAHN, Charles H. A arte e o pesamento de Heráclito: uma edição dos fragmentos com tradução e comentário de Charles H. Kahn. Tradução Élcio de Gusmão Verçosa Filho. São Paulo: Paulus, 2009.

KRASNER, David; SALTZ, David. Staging Philosophy: intersections of theater, performance, and philosophy. Published by the University of Michigan Press. 2009.

MACHADO, Irene. Escola de Semiótica - A Experiência de Tartú-Moscou para o Estudo da Cultura. São Paulo: Ateliê Editorial, 2003.

MACHADO, Roberto. Deleuze, a arte e a Filosofia. Rio de Janeiro: Ed. Jorge Zahrar, 2010.

MARX, Karl; ENGELS, Friedrich. Escritos sobre literatura. Buenos Aires: Colihue, 2003.

MEDEIROS, Jorginho; TIÃOZINHO; TOCO. Chuê... Chuá... As águas vão rolar. Intérprete: Paulinho Mocidade. In: SAMBAS DE ENREDO 1991. [S.I.]: RCA, 1991. Lado A, faixa 1.

OLINTO, Marcelo. Apêndice I - Entrevista com Marcelo Olinto. In: SILVA, Carlos Eduardo da. A dinâmica das relações interpessoais em Teatro de grupo: pressões externas e tensões internas na experiência de coletivos teatrais brasileiros. 268 f. il. 2014. Dissertação (Mestrado) - Escola de Teatro, Universidade Federal da Bahia, Salvador, 2014.

PAREYSON, Luigi. Os problemas da estética. Tradução de Maria Helena Nery Garcez. 3.ed. São Paulo: Martins Fontes, 1997.

PAREYSON, L. Estética: teoria da formatividade. Petrópolis: Vozes, 1993.

TURNER, Victor. The Antropology of Performance. New York: PAJ Publications, 1987. 
ZUMTHOR, Paul. Introduction à la poésie orale. Paris: Editions du Seuil, 1983.

Recebido: 16/07/2017

Aprovado: 01/09/2017 